\title{
Evolution of Atmospheric Total Organic Carbon from Petrochemical Mixtures
}

\author{
Kun Li,* Jeremy J. B. Wentzell, Qifan Liu, Amy Leithead, Samar G. Moussa, Michael J. Wheeler, \\ Chong Han, Patrick Lee, Shao-Meng Li, and John Liggio*
}

Cite This: Environ. Sci. Technol. 2021, 55, 12841-12851

Read Online

\section{ACCESS | Lill Metrics \& More | 回 Article Recommendations ｜（） Supporting Information}

ABSTRACT: Reactive organic compounds play a central role in the formation of ozone and secondary organic aerosols. The ability to accurately predict their fate, in part, relies upon quantitative knowledge of the chemical and physical parameters associated with the total organic carbon (TOC), which includes both precursors and oxidation products that evolve in the atmosphere over short to long time scales. However, such knowledge, obtained via limited carbon closure experiments, has not been attained for complex anthropogenic emissions. Here we present the first comprehensive characterization of TOC in the atmospheric oxidation of organic vapors from light and heavy oil mixtures associated with oil sand

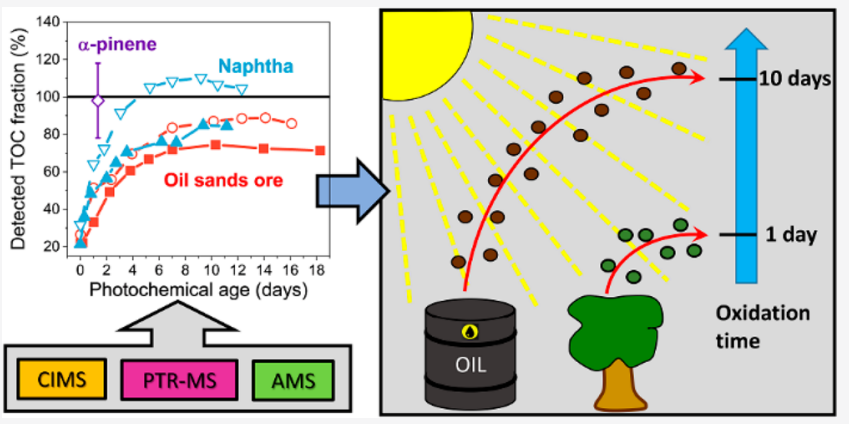
operations. Despite the complexity of the investigated oil mixtures, we are able to achieve carbon closure $(83-116 \%)$ within the uncertainties $( \pm 20 \%)$, with the degree of the closure being dependent upon the vapor composition and $\mathrm{NO}_{x}$ levels. In contrast to biogenic precursors (e.g., $\alpha$-pinene), the photochemical time scale required for a largely complete oxidation and evolution of chemical parameters is very long for the petrochemical vapors (i.e., $\sim 7-10$ days vs $\sim 1$ day), likely due to the lower initial precursor reactivity. This suggests that petrochemical emissions and their impacts are likely to extend further spatially than biogenic emissions, and retain more of their complex composition and reactivity for many days. The results of this work provide key parameters to regional models for further improving the representation of the chemical evolution of petrochemical emissions.

KEYWORDS: atmospheric oxidation, total organic carbon, carbon closure, oil sands, petrochemical emissions, $\mathrm{NO}_{x}$

\section{INTRODUCTION}

Organic carbon (OC), as the fuel for atmospheric chemistry, plays a key role in natural and anthropogenic emissions, atmospheric reactivity (mainly with $\mathrm{OH}$ radicals), and the formation of secondary pollutants, e.g., ozone and secondary organic aerosols (SOA). ${ }^{1}$ Freshly emitted OC is mainly in the gas phase ${ }^{2}$ and can undergo multigeneration oxidation to form increasingly oxygenated, lower-volatility compounds, some of which will partition into the particle phase to form SOA. ${ }^{3}$ However, given the complex composition of gas-phase OC (gOC) and particle-phase OC (pOC) (at least $10^{5}$ individual chemical species), ${ }^{4}$ understanding their molecular-level composition and evolution, including carbon closure, during atmospheric oxidation is highly challenging. ${ }^{1}$ Previous studies have primarily focused on the kinetics and mechanisms of the gOC oxidation processes, in which only the consumption rates of precursors and/or the concentrations of specific products are quantified, ${ }^{1,5-7}$ and where the sum of these products often cannot achieve carbon closure. ${ }^{1,4,8-10}$ This suggests that there are many undetected/uncharacterized products, whose molecular formulas, oxidation states, volatilities, and reactivities are unknown. The ill-defined chemical nature of gOC oxidation products represents a significant gap in the understanding of the properties of $\mathrm{OC}^{11,12}$ andimplies that the fates of organic pollutants, and their potential human, climate, and environmental impacts, are only partly understood. The gap further underscores a need for a more holistic perspective on atmospheric $\mathrm{OC}$, in which all species that make up the total are determined ${ }^{1,2,13,14}$ (i.e., total organic carbon (TOC $=$ gOC + pOC)). Recent advances in state-of-the-art mass spectrometers have made real-time detection of speciated TOC feasible, and the combination of these techniques can significantly improve the understanding of atmospheric TOC and its temporal/chemical evolution. ${ }^{10,15-17}$

Atmospheric TOC has various natural and anthropogenic emission sources. Fossil fuel, as the main global energy supply for the past two centuries, ${ }^{18}$ is one of the most important

Received: April 21, 2021

Published: September 16, 2021

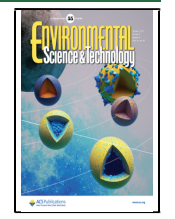


anthropogenic TOC emission sources. ${ }^{1}$ The world crude oil consumption has continued to increase over the past several years, ${ }^{19}$ and with that, oil production from unconventional sources, e.g., shale oil and oil sands (OS), has also increased significantly. ${ }^{20}$ One of the largest producers of unconventional/heavy oil in the world is the OS in Alberta, Canada, with a production of 3.1 million barrels of oil per day as of $2019 .^{21}$ These large production rates have been demonstrated to be associated with large emissions of volatile organic compounds (VOCs), particularly from open-pit mining facilities. ${ }^{22}$ The presence of less volatile gas-phase precursors (i.e., intermediate-volatility and semivolatile organic compounds, IVOCs and SVOCs) has also been observed and inferred through box modeling ${ }^{23,24}$ and measured in laboratory emissions of various OS precursor materials. ${ }^{25,26}$ These precursor emissions have been demonstrated to lead to significant amounts of SOA. ${ }^{22-26}$ While measured SOA represents an important type of atmospheric end product, a much larger pool of gOC likely exists, which itself will evolve downwind. The chemical evolution of this gOC has not been explored, and the neglect of this process hinders a complete understanding of the fate of the majority of TOC from large petrochemical sources such as the OS.

Although real-time measurements of the TOC, its evolution, and carbon closure for all sources are of significance to atmospheric chemistry, they have only been performed in laboratory experiments for relatively simple precursors and for limited ages (e.g., cyclohexene ozonolysis for $<1 \min ^{27}$ and $\alpha$ pinene photooxidation for $\sim 1$ day $^{10}$ ). An understanding of the chemical evolution of anthropogenic complex TOC mixtures (e.g., OS emissions) during its oxidation in the atmosphere over long time scales is currently lacking and experiments designed for this purpose have not been attempted. In addition, other factors can further complicate the understanding of the evolution of TOC. For example, the level of nitrogen oxide $\left(\mathrm{NO}_{x}\right)$ is known to play a key role in influencing gas-phase oxidation and chemical composition ${ }^{28,29}$ as well as SOA yields and properties. ${ }^{30,31}$ The presence of $\mathrm{NO}_{x}$ may also impact the ability to achieve a carbon closure via realtime measurement techniques, as gOC oxidation in the presence of $\mathrm{NO}_{x}$ is likely to form oxidized compounds with substantial differences in key TOC parameters (e.g., molecular size, volatility, and oxidation level), which have not been explored. Taken together, the lack of empirical data on the evolution of anthropogenic TOC over long photochemical time scales and in the presence of $\mathrm{NO}_{x}$ limits the understanding of its atmospheric processing to key end points, specifically ozone and SOA and their impact on deposition to ecosystems.

Here, we present the results of real-time measurements of the TOC formed during the laboratory oxidation of petroleum vapors from samples typical of the OS industry: OS ore and naphtha, both of which are complex mixtures. OS ore is mainly composed of bitumen (a material similar to asphalt used in road construction), ${ }^{32}$ which has a carbon-number distribution as high as $\mathrm{C}_{20}-\mathrm{C}_{30} \cdot{ }^{24,33}$ Naphtha is a widely used solvent and diluent in heavy oil (including oil sands) industry, which comprises hydrocarbons with a carbon-number distribution similar to that of gasoline $\left(\mathrm{C}_{6}-\mathrm{C}_{10}\right) \cdot{ }^{25,34}$ Vapors from both materials represent the dominant emissions of carbon from the OS industry (i.e., mine faces, processing, and tailings ponds), ${ }^{22}$ whose oxidation products may dominate downwind human and ecosystem exposure. These materials are also similar in carbon distribution to other widely used petroleum products (e.g., diesel and gasoline ${ }^{25,34,35}$ ) and provide a representative contrast between heavy and light petroleum products with respect to their oxidative evolution. We make use of state-ofthe-art mass spectrometers to track the TOC from these petrochemical precursors during their medium to long term oxidation (up to $>10$ days), revealing the impacts of precursor type and $\mathrm{NO}_{x}$ level on the ability to achieve a carbon closure and on the key chemical parameters (e.g., carbon number, oxidation state, volatility, and lifetime) of the oxidized product mixture, which can be ultimately used within photochemical models.

\section{METHODS}

2.1. Experimental Conditions. Photooxidation experiments were conducted using the Environment and Climate Change Canada Oxidation Flow Reactor (ECCC-OFR). ${ }^{25,26}$ The OFR was previously shown to have minimal wall losses and relatively high SOA yields compared to previous OFRs, likely due to improvements in design which minimize wall loss. ${ }^{25}$ The OFR was operated in continuous mode, and the duration of each oxidation step was 40-45 $\mathrm{min}$. The volume of the OFR is $16 \mathrm{~L}$, and with a flow rate of $6 \mathrm{~L} \mathrm{~min}^{-1}$, it achieves an average residence time of $160 \mathrm{~s}$. Oxidation was conducted via $\mathrm{OH}$ radicals which were generated through the photolysis of $\mathrm{O}_{3}$ (at $254 \mathrm{~nm}$ ) followed by reaction with water vapor. Differing $\mathrm{OH}$ exposures (i.e., photochemical ages) were realized by varying the light intensity (through applied voltage changes). The $\mathrm{OH}$ exposure $\left(2.2 \times 10^{10}-2.4 \times 10^{12}\right.$ molecules $\mathrm{cm}^{-3} \mathrm{~s}$ ) was estimated through the decay of $\mathrm{CO}$ in separate experiments. ${ }^{25,26}$ For high- $\mathrm{NO}_{x}$ experiments, gaseous $\mathrm{NO}$ was generated in situ through the photolysis of ozone and subsequent reaction with $\mathrm{N}_{2} \mathrm{O} .^{26,36}$ The $\mathrm{N}_{2} \mathrm{O}$ concentration at each different $\mathrm{OH}$ exposure was varied in the range 1.3-7\% to ensure that $\sim 95 \%$ of the peroxy radicals $\left(\mathrm{RO}_{2}\right)$ reacted with NO, estimated using a box model described previously. ${ }^{26,37}$ The experiments were performed at room temperature $(\sim 20$ ${ }^{\circ} \mathrm{C}$ ) and $50 \%$ relative humidity. Vapors from OS ore and naphtha samples were introduced into the OFR via a small flow of zero air passed over the headspace of the sample material maintained at room temperature. Polydisperse ammonium sulfate aerosols $\left(\sim 20 \mu \mathrm{g} \mathrm{m}^{-3}\right)$ were used as seed particles for all the experiments. Additional details with respect to experimental conditions and potential limitations of the OFR are given in the Supporting Information.

2.2. Gas and Aerosol Measurements. The TOC concentration associated with the precursors (i.e., $100 \%$ gOC) used as input to the OFR was measured using a total hydrocarbon (THC) detection system ${ }^{25,38}$ based upon catalytic conversion of organic gases to $\mathrm{CO}_{2}$ and its subsequent measurement. The precursor volatility distribution was measured via collection onto sorbent tubes followed by analysis with a thermal-desorption gas chromatography-mass spectrometer (TD-GCMS, Agilent), via a method described previously. ${ }^{24,25}$ Particle size distributions were measured with a scanning mobility particle sizer (SMPS, TSI), and particle elemental ratios $(\mathrm{O} / \mathrm{C}, \mathrm{H} / \mathrm{C}$, and $\mathrm{N} / \mathrm{C})$ were determined using a long time-of-flight aerosol mass spectrometer (LTOFAMS, Aerodyne). ${ }^{25,39}$ The particle density (1.4-1.63, see Table S1) of OA calculated from the vacuum aerodynamic diameter (obtained from the AMS) and the electric mobility diameter (obtained from the SMPS) from previous unseeded experiments $^{25,26}$ were used to determine the mass concen- 

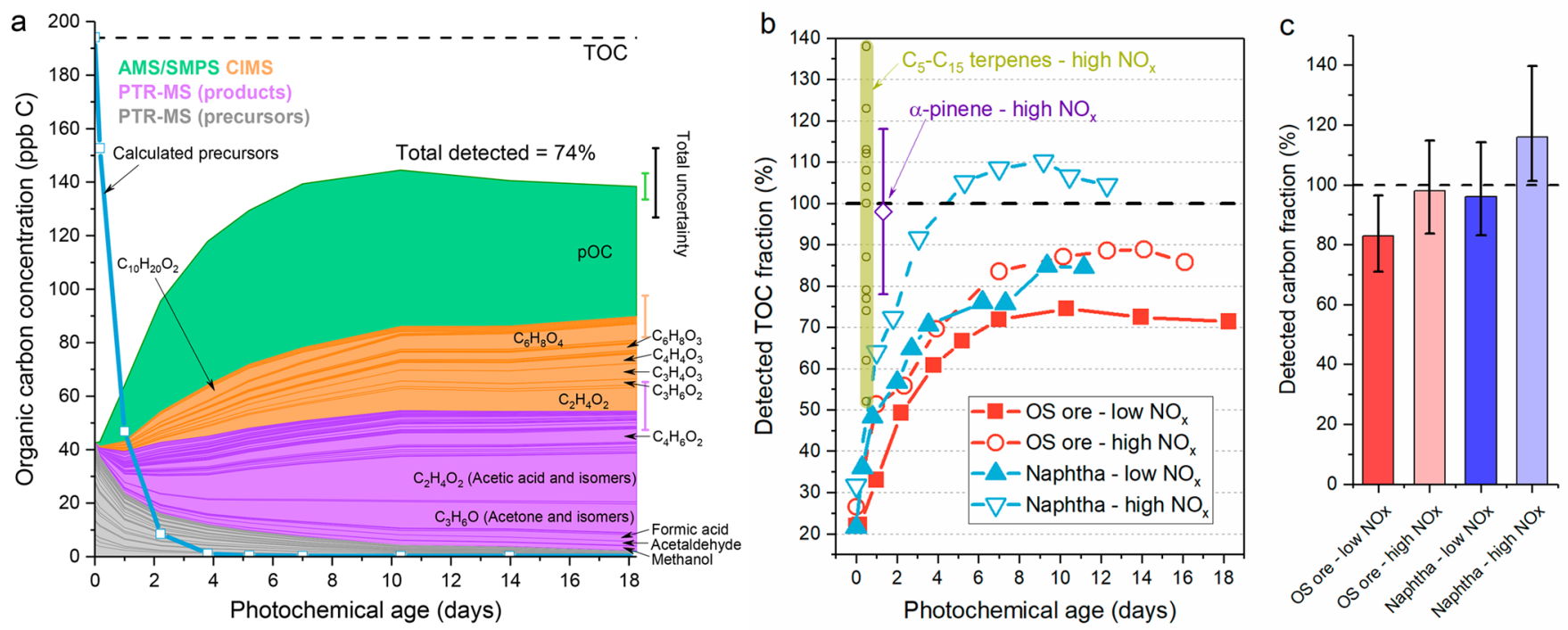

Figure 1. Measured carbon during the photooxidation of petrochemical sources. (a) Measured organic carbon concentration for OS ore vapor oxidation experiment under low- $\mathrm{NO}_{x}$ conditions, colored by the instrument by which it was measured. The TOC input concentration measured before oxidation (dashed line) is also shown. The uncertainty of each instrument and the total uncertainty are shown on the right axis. The ions in gray $\left(\mathrm{C}_{x} \mathrm{H}_{y}^{+}\right)$are precursor fragment ions measured by PTR-MS. ${ }^{52}$ The photochemical age is calculated using the measured OH exposure and an average $\mathrm{OH}$ concentration of $1.5 \times 10^{6}$ molecules $\mathrm{cm}^{-3}$ in the atmosphere. ${ }^{51}$ The calculated concentration of precursors based on the $k_{\mathrm{OH}}$ of $n$ decane is also shown (see the Supporting Information (section S4.2)). The corresponding plots for the other three experiments (OS ore-high $\mathrm{NO}_{x}$, naphtha-low $\mathrm{NO}_{x}$, and naphtha-high $\mathrm{NO}_{x}$ ) are given in Figure S6. (b) Fraction of detected TOC (i.e., TOOC/TOC) for the four photooxidation experiments in this study and comparison with previous studies for biogenic terpenes. ${ }^{9,10}$ In Lee et al., ${ }^{9}$ photochemical age is not provided but is generally in the early stage of oxidation; therefore, a photochemical age of 0.5 day is assumed for these $C_{5}-C_{15}$ terpenes. $(c)$ Fraction of detected carbon at the maximum photochemical ages for the four experiments, after considering the contributions of $\mathrm{CO}$ and $\mathrm{CO}_{2}$.

tration of OA from the volume distribution. This derived OA mass concentration (see Table S1), together with the AMSderived $\mathrm{O} / \mathrm{C}, \mathrm{H} / \mathrm{C}$, and $\mathrm{N} / \mathrm{C}$ ratios, was used to calculate the pOC concentration during the experiments. A proton transfer reaction time-of-flight mass spectrometer (PTR-TOF-MS, Ionicon $)^{40}$ was used to measure reduced and lightly oxygenated gOC, and a high-resolution time-of-flight chemical ionization mass spectrometer (HR-TOF-CIMS, Aerodyne), using $\mathrm{I}^{-}$as the reagent ion, ${ }^{41}$ was used to measure medium and highly oxygenated gOC. The PTR-MS was calibrated with 15 authentic standards and a rate-transmission method for unknown species. ${ }^{42}$ The CIMS was calibrated with 23 authentic standards and a voltage-scanning method for compounds of unknown structures, ${ }^{10,43,44}$ which is the first full calibration for I-CIMS with the added constraints from the use of authentic standards. The uncertainty associated with the OC concentration measured by each instrument was $\pm 10 \%$ for the SMPS/AMS, ${ }_{-10}^{+30} \%$ for the PTR-MS, and $\pm(20-35 \%)$ for the CIMS. These uncertainties contribute to an overall uncertainty of ${ }_{-(8-10)}^{+(10-18)} \%$ for total observed OC (herein referred to as TOOC), which corresponds to ${ }_{-(6-10)}^{+(7-18)} \%$ for TOC (Table S4). Additional details of instrument calibrations and the derivation of uncertainties are given in the Supporting Information (section S2).

2.3. Chemical Parameter Determination. The carbon oxidation state $\left(\mathrm{OS}_{\mathrm{C}}\right)$ in the gas and particle-phase was determined from elemental ratios; ${ }^{45}$ see the Supporting Information (section S1.2) for details. The volatilities (saturation concentration, $C^{*}$ ) of the measured compounds of known chemical structures were obtained from the PubChem database ${ }^{46}$ and are provided in Table S4. The $C^{*}$ values of the gas-phase compounds of unknown structures were calculated based upon their molecular formulas, using a parametrization described previously ${ }^{47}$ which utilizes the number of carbon, oxygen, and nitrogen atoms $\left(n_{\mathrm{C}}, n_{\mathrm{O}}\right.$, and $\left.n_{\mathrm{N}}\right)$ in the molecules. The reaction rate constants with $\mathrm{OH}$ $\left(k_{\mathrm{OH}}\right)$ for compounds of known chemical structures were obtained from the National Institute of Standards and Technology Chemical Kinetics Database ${ }^{48}$ and relevant literature, ${ }^{49}$ and they are provided in Table S5. The $k_{\mathrm{OH}}$ for gas-phase oxidation products of unknown chemical structures were estimated from $n_{\mathrm{C}}, n_{\mathrm{O}}$, and $\mathrm{O} / \mathrm{C}$ as described elsewhere. ${ }^{50}$ The atmospheric lifetime was then calculated as

$$
\tau_{\mathrm{OH}}=\left(k_{\mathrm{OH}} \overline{[\mathrm{OH}]}\right)^{-1}
$$

assuming an average $\mathrm{OH}$ concentration of $1.5 \times 10^{6}$ molecules $\mathrm{cm}^{-3} .51$

\section{RESULTS AND DISCUSSION}

3.1. Carbon Closure. The OC concentration from the measured OS ore precursors and products as a function of simulated photochemical age in the OFR is shown in Figure la, under low- $\mathrm{NO}_{x}$ conditions. The equivalent results for OS ore-high- $\mathrm{NO}_{x}$, naphtha-low- $\mathrm{NO}_{x}$, and naphtha-high- $\mathrm{NO}_{x}$ experiments are shown in Figure S6. Contributions of the species from each instrument to TOOC and relative to the input TOC, with corresponding uncertainties, are shown in Table S4. It should be noted that all the carbon closure results are based on the online instrument ensemble deployed in this study. The use of offline techniques (e.g., GC) is beyond the scope of this study, but they are expected to be most sensitive to hydrocarbon species and not oxidized products as investigated here. Prior to oxidation, the PTR-MS can detect $\sim 20-30 \%$ of the gOC for both OS ore and naphtha precursors (Figure 1a and Figure S6), which are mainly present as fragment ions $\left(\mathrm{C}_{x} \mathrm{H}_{y}^{+}\right)$of alkanes and cycloalkanes. ${ }^{52}$ This 

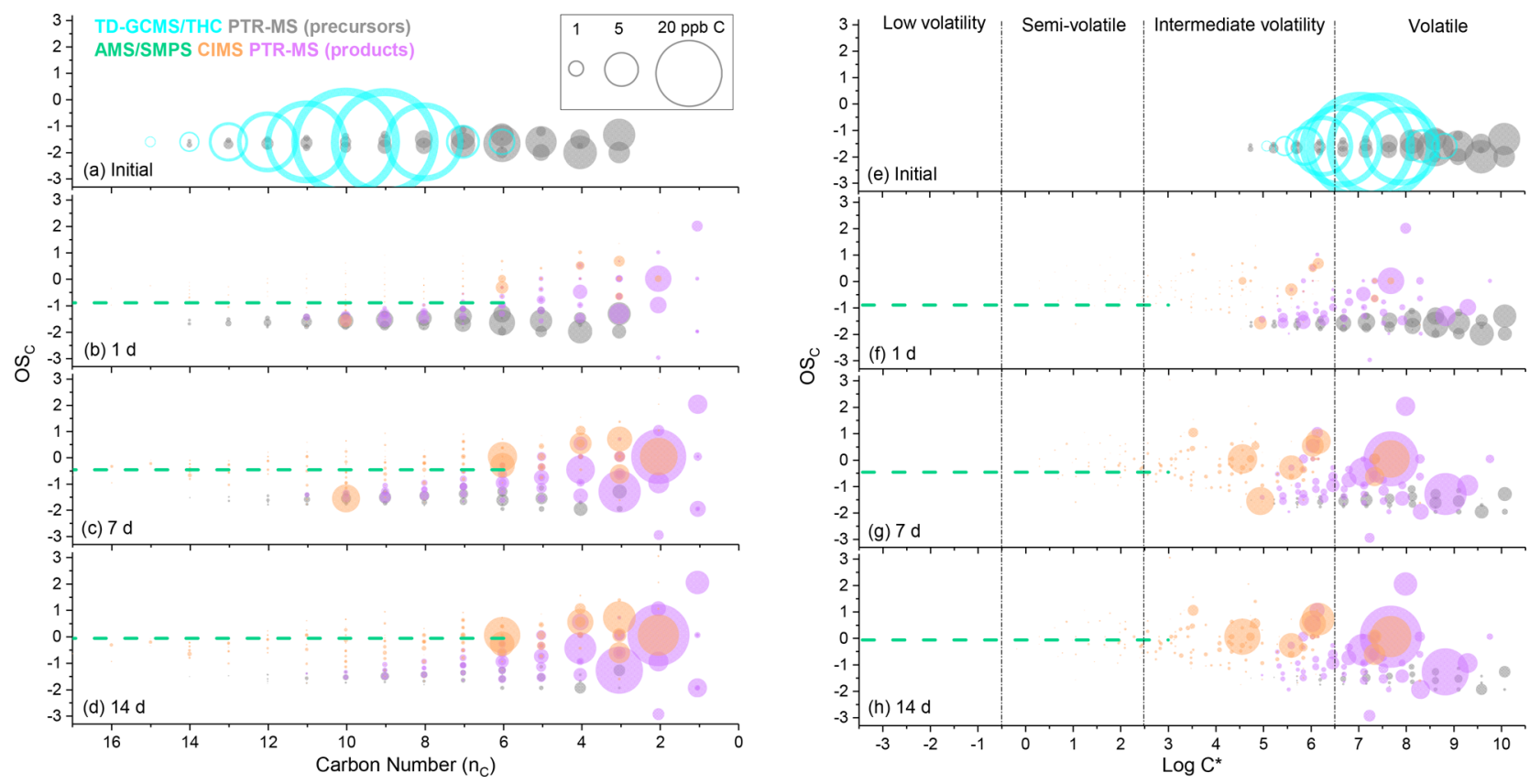

Figure 2. Carbon oxidation state $\left(\mathrm{OS}_{\mathrm{C}}\right)$ as a function of carbon number $(\mathrm{a}-\mathrm{d})$ and volatility (saturation concentration, $\mathrm{C}^{*}$; e-h) for organic compounds in the low- $\mathrm{NO}_{x}$ photooxidation of OS ore. The four panels from top to bottom are at zero (a, e), low ( 1 day; b, f), medium (7 days; $c$, $\mathrm{g}$ ), and high (14 days; d, h) photochemical ages, respectively. The species (ions) are colored by the instrument used to make the measurement. The cyan open circles in the top panels ( $a, e)$ represent the TOC concentrations before oxidation, which were only measured for precursors. Each solid circle represents one elemental formula (ion) measured by PTR-MS or CIMS. The areas of the circles represent their carbon concentrations (in parts per billion C). For pOC, only the average $\mathrm{OS}_{\mathrm{C}}$ is measured, and we assume a carbon number $>6$ and $C^{*}$ of $<10^{3}$ for aerosols. The corresponding plots for OS ore-high- $\mathrm{NO}_{x}$, naphtha-low- $\mathrm{NO}_{x}$, and naphtha-high- $\mathrm{NO}_{x}$ experiments are given in Figures $\mathrm{S} 7-\mathrm{S} 9$.

indicates that $\sim 70-80 \%$ of the carbon associated with the primary OS emissions in these experiments remains undetected by PTR-MS (apart from the total), which is significantly different from primary biogenic terpene experiments (for which $\sim 100 \%$ of the primary carbon is detected $\left.^{8-10}\right)$.

Upon oxidation, gOC and pOC products are formed and the TOOC increases with increasing photochemical age, until 7-10 equivalent days (Figure $1 \mathrm{a}$ and Figure S6). The relative ability to achieve a total carbon closure in the four photooxidation experiments is shown in Figure $1 \mathrm{~b}$ as a detected fraction of the TOC. It is assumed that there is no overlap between PTR-MS and CIMS species (except for unambiguous species such as formic acid, in which the PTRMS data was used), which is a commonly used assumption in previous studies. ${ }^{10,15-17}$ In this study, the only notable possible overlap is from $\mathrm{C}_{2} \mathrm{H}_{4} \mathrm{O}_{2}$ under low- $\mathrm{NO}_{x}$ conditions (i.e., it is not observed under high- $\mathrm{NO}_{x}$ conditions), which contributes $\sim 4 \%$ of the TOC. Possible overlaps from other molecular formulas together contribute $<2 \%$ of the TOC. Therefore, these potential overlaps do not significantly influence the results here. Figure $1 \mathrm{~b}$ generally illustrates that the maximum detected TOC fraction ranges from $\sim 75$ to $\sim 110 \%$ for the oxidation of OS precursors under various $\mathrm{NO}_{x}$ conditions.

The ability to achieve carbon closure in previous smog chamber studies for biogenic terpene precursors ${ }^{9,10}$ is also shown in Figure 1b. Comparison between different reactors (i.e., chamber versus OFR) is possible if both can adequately simulate atmospheric reactions. ${ }^{53}$ As discussed in the Supporting Information (section S3.2), working conditions were optimized for the ECCC-OFR to minimize the potential for atmospherically irrelevant reactions. Therefore, the differences here are likely valid regardless of reactor type. Isaacman-
VanWertz et al. ${ }^{10}$ found that carbon closure can be achieved (98 $\pm 20 \%$ ) within $\sim 1.3$ photochemical days in the high- $\mathrm{NO}_{x}$ $\mathrm{OH}$ oxidation of $\alpha$-pinene, while approximate carbon closure here is only attained $(85-110 \%)$ after $\sim 7-10$ photochemical days during the high- $\mathrm{NO}_{x} \mathrm{OH}$ oxidation of OS precursors. This difference in the photochemical age required to achieve measured carbon closure reflects the $\mathrm{OH}$ reactivity of the precursors and their subsequent products. The $k_{\mathrm{OH}}$ of $\alpha$-pinene is $\sim 5-8$ times higher than those of $C_{10}$ and $C_{7}$ alkanes ${ }^{49}$ (the average carbon numbers of $\mathrm{OS}$ ore and naphtha, respectively $\left.^{25}\right)$. In addition, as the structure of $\alpha$-pinene is more complex than those of alkanes, i.e., a bicyclic structure with a double bond, the early generation products of $\alpha$-pinene are expected to retain some of these structures (e.g., cyclic structure and/or double bond $)^{54,55}$ and thus have higher $k_{\mathrm{OH}}$ values than products from simple alkanes. ${ }^{56}$ For example, the $k_{\mathrm{OH}}$ of pinonaldehyde (the main early generation product of $\alpha$ pinene; $k_{\mathrm{OH}}=4.4 \times 10^{-11} \mathrm{~cm}^{3}$ molecule $\left.\mathrm{s}^{-1} \mathrm{~s}^{-1}\right)$ is $3-4$ times higher than those of $\mathrm{C}_{10}$ ketones (early generation products of linear and branched $\mathrm{C}_{10}$ alkanes; $k_{\mathrm{OH}}=(1.1-1.3) \times 10^{-11} \mathrm{~cm}^{3}$ molecule $\left.\mathrm{s}^{-1}\right){ }^{49,57}$ As a result, a higher $\mathrm{OH}$ exposure is required for these OS precursors to reach a similar oxidation state as $\alpha$-pinene (see section 3.2). The current results are highly consistent with a recent explicit model study which demonstrated that TOC from decane (a typical anthropogenic precursor similar to $\mathrm{OS}$ precursors ${ }^{22,25}$ ) will retain high $\mathrm{OH}$ reactivity after $\sim 10$ days of oxidation, while TOC from isoprene (a typical biogenic precursor) will have a reduced $\mathrm{OH}$ reactivity after $\sim 1$ day of oxidation. ${ }^{58}$

The undetected OC at lower photochemical ages is partially from unmeasured precursors, which are most important at $<1-2$ days (see the Supporting Information (section S4.2), Figure 1a, and Figure S6). However, most of the undetected 

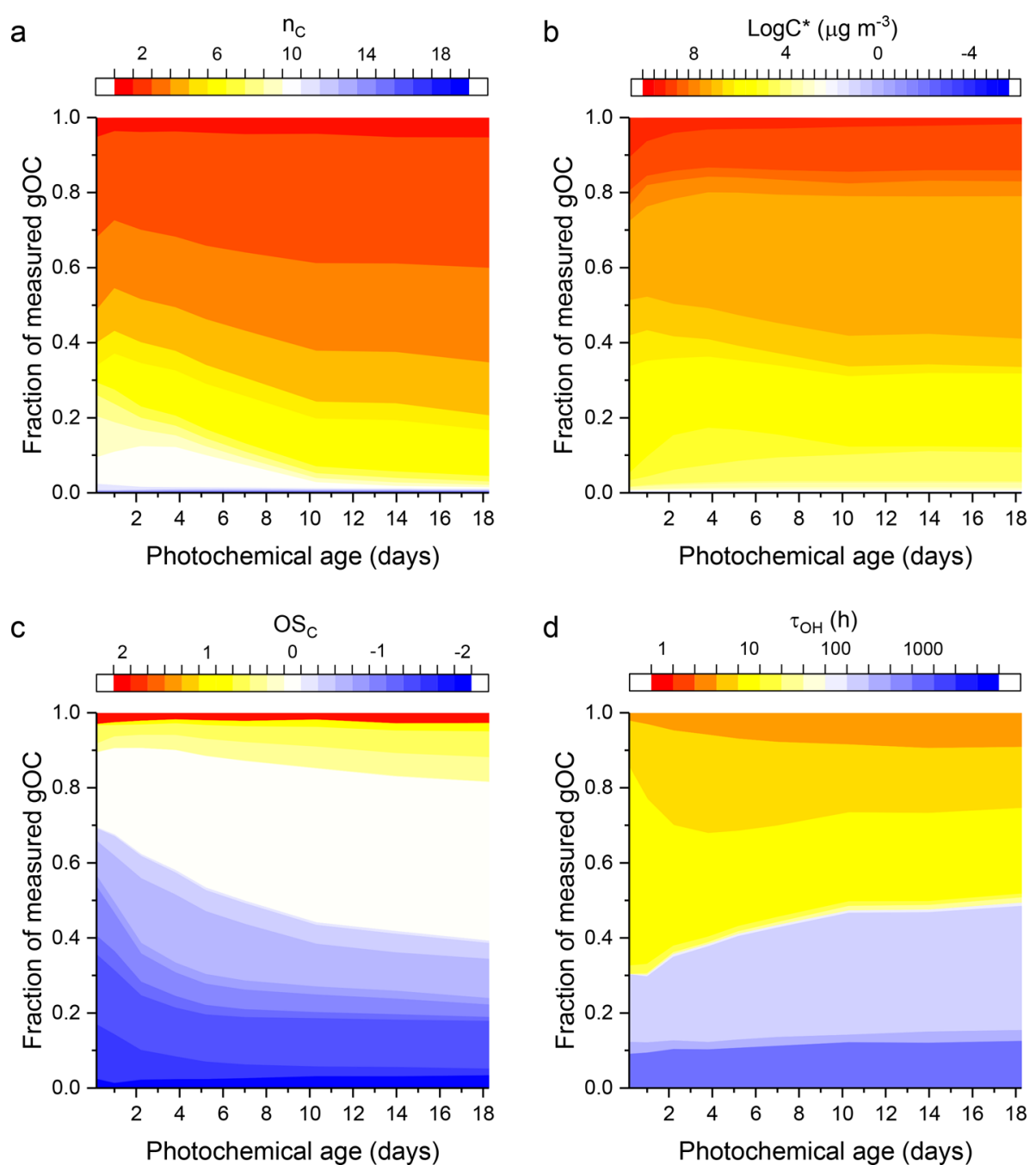

Figure 3. Distribution of key chemical parameters of measured gas-phase products in the low- $\mathrm{NO}_{x}$ photooxidation of OS ore vapor. (a) Carbon number, $n_{\mathrm{C}}$ (b) Volatility in terms of saturation concentration, $C^{*}$. (c) Carbon oxidation state, $\mathrm{OS}_{\mathrm{C}}$. (d) Atmospheric lifetime against OH oxidation, $\tau_{\mathrm{OH}}$. As the AMS can only provide bulk chemical properties without molecular formulas, the distribution of chemical parameters associated with pOC is not shown here. The carbon-weighted average data of these parameters are shown in Figure S13. The corresponding plots for OS ore-high- $\mathrm{NO}_{x}$, naphtha-low- $\mathrm{NO}_{x}$, and naphtha-high- $\mathrm{NO}_{x}$ experiments are given in Figures S10-S12.

OC compounds are likely to be lightly functionalized $\left(n_{\mathrm{O}} \leq 2\right.$ if without nitrogen), high-carbon-number products (especially at 2-5 days), similar to the suggestion from previous work investigating the oxidation of $\alpha$-pinene. ${ }^{10}$ PTR-MS and CIMS are unable to capture these compounds due to technical limitations. However, as the oxidation process continues (i.e., photochemical age increases), these compounds become more oxygenated, falling within a range which can be measured by CIMS, and/or become smaller due to fragmentation reactions, allowing them to be measured by PTR-MS. As a result, the undetected TOC fraction decreases significantly within the photochemical ages of 0-7 days (Figure 1a,b).

It should also be noted that inorganic carbon compounds (i.e., $\mathrm{CO}$ and $\mathrm{CO}_{2}$ ) are not included in Figure 1a,b and the discussion above. However, $\mathrm{CO}$ and $\mathrm{CO}_{2}$ are also end products of oxidation and can contribute to the carbon closure. The measured CO contribution in this study is $6 \pm 1 \%$ at $>7$ photochemical days, slightly higher than a previous smog chamber study of $\alpha$-pinene at $\sim 1.3$ days $(\sim 4 \%) .{ }^{10}$ Unfortunately, $\mathrm{CO}_{2}$ was not measured in this study. Assuming that the $\mathrm{CO}_{2}$ fraction is similar to that of $\mathrm{CO}$ but has $100 \%$ uncertainty (i.e., contribution $6 \pm 6 \%$ ), ${ }^{10,59,60}$ the total contribution of inorganic carbon to the TOC is $12 \pm 7 \%$. Accounting for this contribution results in a further improved carbon closure, from $\sim 71-104 \%$ to $\sim 83-116 \%$ at the maximum photochemical ages as shown in Figure 1c.

3.2. Evolution of OC Chemical Properties. In addition to carbon closure, we also studied the chemical properties of OC. A general examination of the evolution of OC chemical properties is shown in Figure 2, which shows snapshots of $\mathrm{OS}_{\mathrm{C}}$ as a function of carbon number $\left(n_{\mathrm{C}}\right)$ and volatility (in terms of saturation concentration, $C^{*}$ ) for all individual compounds in the low- $\mathrm{NO}_{x}$ photooxidation of OS ore vapor. Analogous plots associated with the other three precursor/ $\mathrm{NO}_{x}$ experiments are shown in Figures S7-S9. The top panels (a, e) of Figure 2 and Figures $57-S 9$ show the distribution of $\mathrm{OS}_{\mathrm{C}}, n_{\mathrm{C}}$, and $\mathrm{C}^{*}$ of the vapors before oxidation. Offline TD-GCMS measurements (blue circles in top panels) indicate that the majority of precursors have an $n_{C}$ in the range of $8-12$ (average of 10) for the OS ore vapor and 6-8 (average of 7) for the naphtha vapor. At a relatively low photochemical age (0.8-1 day, panels $b, f$ ), oxygenated (higher $\mathrm{OS}_{\mathrm{C}}$ ) products are formed 

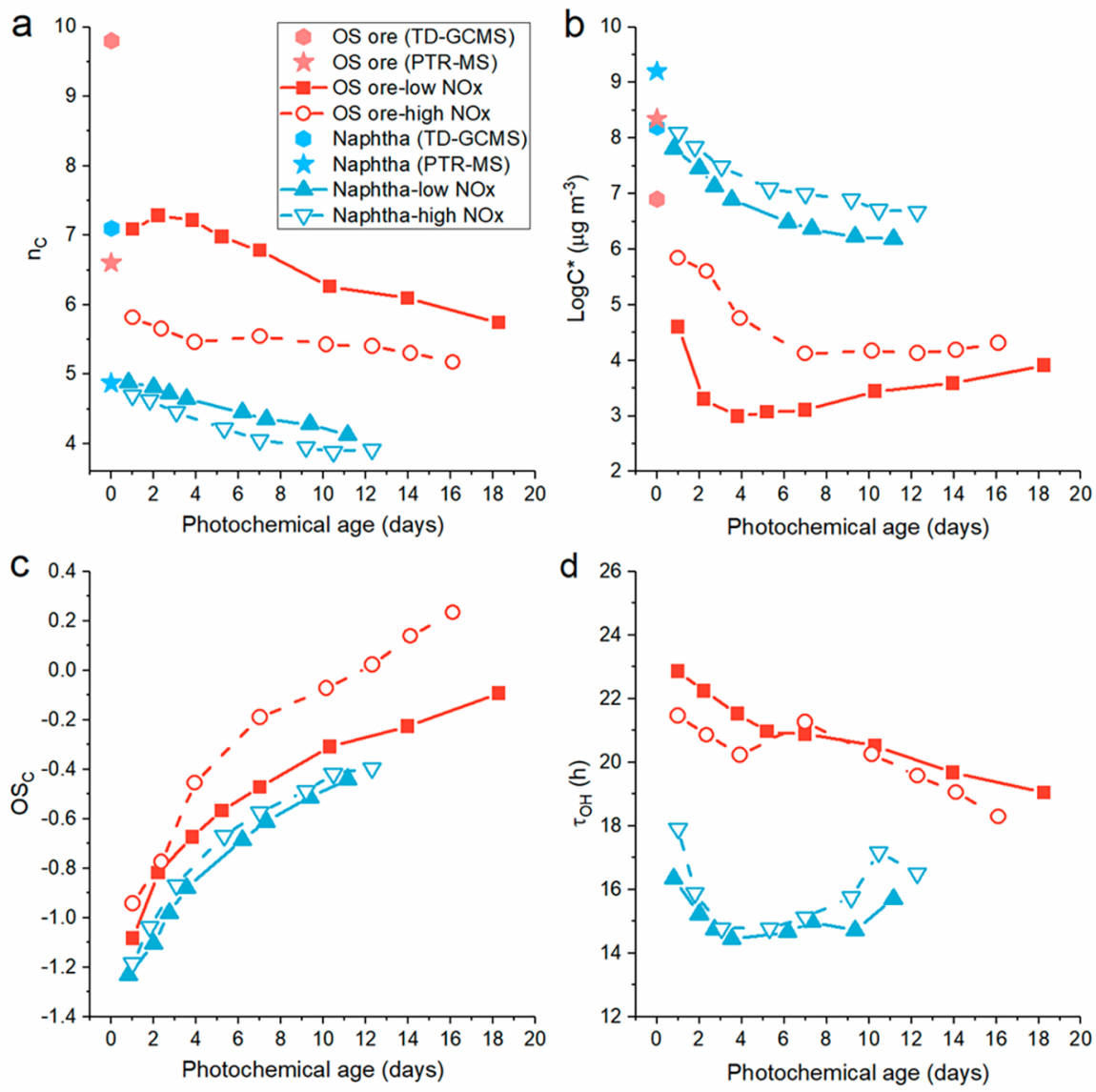

Figure 4. Carbon-weighted averages of key chemical parameters of total observed OC (TOOC) in four photooxidation experiments. (a) Carbon number, $n_{\mathrm{C}}$ (b) Volatility in terms of saturation concentration, $C^{*}$. (c) Carbon oxidation state, $\mathrm{OS}_{\mathrm{C}}$. (d) Atmospheric lifetime against OH oxidation, $\tau_{\mathrm{OH}}$. In (a) and (b), the average $n_{\mathrm{C}}$ and $\log C^{*}$ for precursor ions measured by TD-GCMS and PTR-MS are also shown.

with similar and/or lower $n_{\mathrm{C}}$ values. These products are mainly volatile $\left(C^{*}>3 \times 10^{6} \mu \mathrm{g} \mathrm{m}^{-3}\right)$ and intermediate-volatility $(3 \times$ $\left.10^{2} \mu \mathrm{g} \mathrm{m}^{-3}<C^{*}<3 \times 10^{6} \mu \mathrm{g} \mathrm{m}^{-3}\right)$ compounds. ${ }^{61}$ Upon further oxidation to a medium photochemical age (5-7 days, panels $c, g$ ), the precursors are entirely consumed, although there are some $\mathrm{C}_{x} \mathrm{H}_{y}{ }^{+}$ions remaining which may be fragmentation ions from products. At the same time, concentrations of most measured products increase dramatically compared to low photochemical age, as do their volatilities, into the semivolatile region $\left(3 \times 10^{-1} \mu \mathrm{g} \mathrm{m}^{-3}<\right.$ $\left.C^{*}<3 \times 10^{2} \mu \mathrm{g} \mathrm{m}^{-3}\right) .^{61}$ Finally, further oxidation beyond 7 days (panels $d, h$ ) only slightly changes the concentration and distribution of the products. This indicates that oxidation prior to $\sim 5-7$ days is most important in altering the composition and properties of TOC from OS precursors, consistent with the trend in carbon closure of Figure 1 and Figure S6.

The evolution of OC shown in Figures $1 \mathrm{a}$ and 2 also provides evidence for the importance of multigeneration oxidation. For example, the oxidation at low to medium photochemical ages can generate lightly oxygenated products with the carbon skeleton of the precursors retained, e.g., $\mathrm{C}_{10} \mathrm{H}_{20} \mathrm{O}_{2}$ in the OS ore oxidation (Figure 1a). The concentrations of these products decrease significantly upon further oxidation, likely forming smaller products due to fragmentation reactions, e.g., $\mathrm{C}_{4}$ and $\mathrm{C}_{6}$ products, acetone, and acetic acid (Figure 1a). Similarly, naphtha experiments exhibit early generation products such as $\mathrm{C}_{7} \mathrm{H}_{14} \mathrm{O}$ and $\mathrm{C}_{7} \mathrm{H}_{12} \mathrm{O}$ (Figure S6a), and their concentrations also decrease with increasing photochemical age. The evolution of some representative products is shown in Figure S5, indicating the formation of early-generation products (peak at $\sim 2$ days with one $\mathrm{O}$ atom, e.g., $\mathrm{C}_{9} \mathrm{H}_{16} \mathrm{O}$ and $\left.\mathrm{C}_{7} \mathrm{H}_{14} \mathrm{O}\right)$, medium-generation products (peak at $\sim 4$ days with two $\mathrm{O}$ atoms, e.g., $\mathrm{C}_{10} \mathrm{H}_{20} \mathrm{O}_{2}$ and $\mathrm{C}_{7} \mathrm{H}_{12} \mathrm{O}_{2}$ ), and late-generation products (peak after 7 days with $\geq 3 \mathrm{O}$ atoms, e.g., $\left.\mathrm{C}_{6} \mathrm{H}_{8} \mathrm{O}_{3}\right)$. The transition from earlygeneration to late-generation products is consistent with the $\mathrm{OH}$ reactivity; the estimated lifetimes due to $\mathrm{OH}$ oxidation $\left(\tau_{\mathrm{OH}}\right)$ of $\mathrm{C}_{10} \mathrm{H}_{20} \mathrm{O}_{2}, \mathrm{C}_{7} \mathrm{H}_{14} \mathrm{O}$, and $\mathrm{C}_{7} \mathrm{H}_{12} \mathrm{O}$ are $\sim 5-10 \mathrm{~h}$, while they are much longer for many multigeneration end products such as acetone and acetic acid (1089 and $231 \mathrm{~h}$, respectively).

Additional insight is gained with respect to the evolution of OC by investigating the full distribution of key chemical parameters $\left(n_{\mathrm{C}}, \log C^{*}, \mathrm{OS}_{\mathrm{C}}\right.$, and $\left.\tau_{\mathrm{OH}}\right)$ of the measured gasphase oxidized products as a function of photochemical age (Figure 3 and Figures S10-S12). The $n_{\mathrm{C}}$ distributions in Figure 3 and Figures S10-S12 indicate that fragmentation reactions play a very important role in the carbon evolution. As shown in Figure 3a, in the low- $\mathrm{NO}_{x}$ oxidation of the OS ore vapors, gOC species with $n_{\mathrm{C}} \geq 8$ (representing the dominant $n_{\mathrm{C}}$ of OS ore precursor vapors) contribute only $\sim 25 \%$ to the gOC products even at the lowest photochemical age. This fraction decreases further to $<5 \%$ at the highest photochemical age, with the majority of the gOC having $n_{\mathrm{C}} \leq 4$. Similarly, in the oxidation of naphtha vapors, the contribution of gOC with $n_{\mathrm{C}} \geq 6$ decreases from $\sim 50$ to $<20 \%$ with the increasing photochemical age in the low- $\mathrm{NO}_{x}$ oxidation of naphtha vapors 
(Figure S11a). However, despite the decreasing $n_{\mathrm{C}}$, the volatility of gOC (Figure $3 \mathrm{~b}$ ) does not significantly increase, likely a result of being offset by the decreasing volatility trend from the monotonically increasing oxygen component (i.e., $\mathrm{OS}_{\mathrm{C}}$, Figure 3c). The carbon-weighted averages (see the Supporting Information (section S4.1)) of these parameters in Figure S13 also exhibit similar trends for all experiments. Finally, the contribution of gOC with longer lifetimes (e.g., $>100 \mathrm{~h}$, such as acetone, formic acid, and acetic acid) continues to increase slowly throughout oxidation (Figure 3d), confirming that multigeneration atmospheric oxidation ultimately leads to more long-lived species. ${ }^{10}$

The detailed distribution of key chemical parameters of gOC products above (i.e., Figure 3 and Figures S10-S12) combined with precursors and pOC data are used to compute a set of carbon-weighted mean values for TOOC under the four experimental conditions, as shown in Figure 4. With increasing photochemical age, TOOC tends to have lower $n_{\mathrm{C}}$, lower volatility, and higher $\mathrm{OS}_{\mathrm{C}}$. While the $\tau_{\mathrm{OH}}$ of TOOC does not show a significant trend in Figure $4 \mathrm{~d}$, the $\tau_{\mathrm{OH}}$ of TOC (including unmeasured carbon; see the Supporting Information (section S4.3)) in Figure S15 generally shows an increasing trend, indicating that oxidation processes generally increase the $\mathrm{OH}$ oxidation lifetime for the products of $\mathrm{OS}$ emissions. Compared to biogenic precursors, the chemical evolution of petrochemical precursors is much slower. For example, the average $n_{\mathrm{C}}$ of TOOC decreases by 5 (from 10 to $5)$ in $\sim 1$ day for $\alpha$-pinene, ${ }^{10}$ while the average $n_{\mathrm{C}}$ of TOOC decreases by $4-5$ (from 10 to 5-6) and by 3 (from 7 to 4 ) in about 10 days for OS ore and naphtha, respectively, indicating a much slower fragmentation rate. Similarly, OS precursors require $\sim 7-10$ days to form products with an average ${ } S_{C}$ similar to the $\sim 1$ day of oxidation of $\alpha$-pinene $(-0.3) .{ }^{10}$

While the above analysis has focused on more general results for the four oxidation experiments, there are important differences in carbon closure and OC chemical properties among the different precursors and different $\mathrm{NO}_{x}$ conditions (as shown in Figures $1 \mathrm{~b}$ and 4). These differences are discussed below.

3.3. Precursor Impacts. The precursor mixture type impacts the ability of the instrument ensemble to achieve carbon closure. As shown in Figure $1 \mathrm{~b}$, the maximum detected fraction of TOC for naphtha vapors $(85-110 \%)$ is $\sim 10-20 \%$ higher than that for OS ore vapors (74-89\%). Although the pOC contribution for naphtha oxidation products is lower than that for OS ore $(10-12 \%$ vs $25 \%$ at the highest photochemical age), the gOC contribution measured by the PTR-MS for naphtha products is much higher than that for OS ore products (55-83\% vs $28-46 \%$, Table S4). A significant fraction of the gOC compounds measured by PTR-MS are identified species with low molecular weight $\left(\mathrm{C}_{1}-\mathrm{C}_{3}\right)$ such as formaldehyde, methanol, acetaldehyde, formic acid, acetone, and acetic acid. The contribution of these species to TOC is $\sim 7-8 \%$ more for products from naphtha vapors relative to OS ore $(25-39 \%$ vs $18-31 \%)$. Other gOC compounds measured by PTR-MS (i.e., unidentified species, detected as elemental formulas but without a defined molecular structure) contribute $20-30 \%$ more to TOC in naphtha experiments relative to OS ore. PTRMS generally favors the detection of lightly oxygenated compounds of small to medium molecular size (in terms of $n_{\mathrm{C}}$ ). The higher contribution of TOC measured by PTR-MS for naphtha experiments relative to OS ore is consistent with the lower $n_{\mathrm{C}}$, higher volatility, and lower $\mathrm{OS}_{\mathrm{C}}$ of TOOC for naphtha vapors compared to OS ore vapors (Figure 4). This precursor dependence is also similar to previous work which indicated that PTR-MS can measure a larger fraction of the gOC for the oxidation of $\mathrm{C}_{10}$ terpenes compared to $\mathrm{C}_{15}$ terpenes. $^{8,9}$

As shown in Figure 4, the type of precursor also impacts the mean chemical parameters. First, the molecular size (i.e., $n_{\mathrm{C}}$ in Figure $4 a$ ) is larger and the volatility (i.e., $\log C^{*}$ in Figure $4 b$ ) is lower for the TOOC of OS ore vapors compared to naphtha vapors throughout the oxidation, which is consistent with the corresponding properties of the precursors. This indicates that lower-carbon-number precursors generally form smaller and more-volatile products. Second, the mean oxidation state of the TOOC for OS ore vapors is higher than that for naphtha vapors (Figure 4c). This is likely due to the different $\mathrm{OH}$ reactivities, as larger molecules (e.g., OS ore vapors and their products) generally react faster than smaller molecules ${ }^{49}$ (e.g., naphtha vapors and their products), generating more-oxygenated products at a similar $\mathrm{OH}$ exposure. However, the precursor dependence of $\mathrm{OS}_{\mathrm{C}}$ for TOOC (i.e., higher $\mathrm{OS}_{\mathrm{C}}$ for OS ore oxidation products) is different from that of pOC (i.e., lower $\mathrm{OS}_{\mathrm{C}}$ for OS ore oxidation products), as shown in Figure S14 and in previous work. ${ }^{26} \mathrm{We}$ attribute this to additional oxidation steps that are required for lower-carbon-number precursors to form compounds with sufficiently low volatility to partition into the particle phase, which leads to higher $\mathrm{OS}_{\mathrm{C}}$ for naphtha-derived pOC relative to $\mathrm{OS}$ ore-derived pOC. For the gOC products (Figure $\mathrm{S} 13$ ), the $\mathrm{OS}_{\mathrm{C}}$ is mainly determined by the $\mathrm{OH}$ reactivity, similar to TOOC. Finally, the TOOC atmospheric lifetime against $\mathrm{OH}$ oxidation $\left(\tau_{\mathrm{OH}}\right)$ for $\mathrm{OS}$ ore vapors is longer than that for naphtha vapors. The higher mean $\tau_{\mathrm{OH}}$ for OS ore oxidation products in Figure $4 \mathrm{~d}$ is likely due to the much higher contribution of long-lived pOC $\left(\tau_{\mathrm{OH}}=69\right.$ days ${ }^{62}$ ), which accounts for $29-35 \%$ of TOOC for OS ore and 9-14\% for naphtha (Table S4).

The results here also indicate that OS ore vapors more readily undergo fragmentation reactions relative to naphtha vapors. The average $n_{\mathrm{C}}$ of TOOC is $\sim 30-40 \%$ lower than the average $n_{\mathrm{C}}$ of the precursor under low- $\mathrm{NO}_{x}$ conditions, i.e., 3-4 carbons for OS ore and $\sim 2-3$ carbons for naphtha (Figure 4a). However, the presence of $\mathrm{NO}_{x}$ reduces the $n_{\mathrm{C}}$ for OS ore $\left(n_{\mathrm{C}}\right.$ difference $\sim 0.6-1.6$ between high and low $\mathrm{NO}_{x}$ ) more significantly than for naphtha $\left(n_{\mathrm{C}}\right.$ difference $<0.4$ between high and low $\mathrm{NO}_{x}$ ), likely indicating a stronger fragmentation effect or different product distributions. The decrease in pOC concentration for OS ore at $>10$ days (Figure $1 \mathrm{a}$ and Figure S6c) is also attributed to fragmentations, ${ }^{25,26}$ which is not observed for naphtha. Additional aspects of the $\mathrm{NO}_{x}$ impacts during these experiments are described below.

3.4. $\mathrm{NO}_{x}$ Impacts. As shown in Figure $1 \mathrm{~b}$, the presence of $\mathrm{NO}_{x}$ enhances the maximum detected fraction of TOC by $\sim 15-25 \%$, which is attributed to an increase in the detectable carbon mass associated with species that are measurable by PTR-MS (Table S4). For identified and unidentified species measured by PTR-MS, the enhancements in TOC fractions are $13-14 \%$ and $5-15 \%$, respectively, indicating that the presence of $\mathrm{NO}_{x}$ largely enhances the formation of $\mathrm{C}_{1}-\mathrm{C}_{3}$ compounds. The presence of $\mathrm{NO}_{x}$ is known to increase the importance of fragmentation reactions through the formation of alkoxy radicals ( $\mathrm{RO}$ ) via $\mathrm{RO}_{2}+\mathrm{NO}$ reactions followed by unimolecular decomposition of $\mathrm{RO},^{26,28,63}$ potentially resulting in lower-carbon-number oxidized species which are more likely to be detected by PTR-MS. 
The average chemical parameters of TOOC are also influenced by the presence of $\mathrm{NO}_{x}$; primarily the molecular size, volatility, and oxidation state (Figure $4 a-c$ ). The lower $n_{\mathrm{C}}$ and higher $\log \mathrm{C}^{*}$ observed under high- $\mathrm{NO}_{x}$ conditions compared to low- $\mathrm{NO}_{x}$ conditions (Figure $4 \mathrm{a}, \mathrm{b}$ ) is attributed to enhanced fragmentation reactions under high- $\mathrm{NO}_{x}$ conditions. Higher $\mathrm{OS}_{\mathrm{C}}$ under high-NO $\mathrm{NO}_{x}$ conditions is observed for both TOOC (Figure 4c) and pOC (Figure S14), indicating that this $\mathrm{NO}_{x}$ dependence is not influenced by partitioning (however, a partitioning effect is observed as a precursor impact above) and that the presence of $\mathrm{NO}_{x}$ influences the oxidation state of both gas-phase and particle-phase products. The cause of the $\mathrm{OS}_{\mathrm{C}}$ difference between high- $\mathrm{NO}_{x}$ and low- $\mathrm{NO}_{x}$ conditions is unclear. It may be a result of differing reaction pathways (e.g., the formation of $\mathrm{RO}$ and its unimolecular decomposition under high- $\mathrm{NO}_{x}$ conditions) or the difference in radical concentration and fates in the OFR under different $\mathrm{NO}_{x}$ conditions. $^{53}$

3.5. Implications. Using a set of state-of-the-art mass spectrometers, we have made the first attempt to provide a carbon closure for $\mathrm{OH}$ oxidation of anthropogenic complex emissions associated with oil sands (OS) heavy and light precursors, and under different $\mathrm{NO}_{x}$ conditions. Despite the large number of precursors associated with the OS complex mixture, we are able to achieve good carbon closure. This ability allows us to investigate the impacts of complex precursor type and $\mathrm{NO}_{x}$ level on the carbon closure. We find that heavier precursors and lower $\mathrm{NO}_{x}$ level lead to a reduction in the detected carbon mass fraction (e.g., only $\sim 75 \%$ of TOC can be detected in the low- $\mathrm{NO}_{x}$ oxidation of OS ore). These results imply that carbon closure will be more difficult to achieve in single precursor experiments for larger molecules (e.g., SVOCs and IVOCs).

The general trends in chemical properties as a function of oxidation are similar to those observed recently for biogenic precursors ${ }^{10}$ in that photochemical reactions ultimately lead to a decrease in carbon number, an increase in oxidation state, and a bifurcation of volatility into low-volatility aerosols and high-volatility oxygenated VOCs. Despite the similarities, there are important differences associated with petrochemical/ anthropogenic precursor oxidation. Most notably, the photochemical time scale of evolution of chemical properties of TOC is long relative to biogenic species (i.e., $\sim 7-10$ days vs $\sim 1$ day). At the same time, the average lifetime $\left(\tau_{\mathrm{OH}}\right)$ of TOC (including unmeasured carbon) stabilizes to $10-15 \mathrm{~h}$ after $\sim 10$ days of oxidation for OS precursors (Figure S15), which is a significantly shorter lifetime than that for $\alpha$-pinene products $(\sim 50 \mathrm{~h})$ after only $\sim 1$ day of oxidation. This indicates that, although TOC from biogenic precursors may have higher reactivity at shorter oxidation time scales (e.g., <1 day), after significant atmospheric oxidation (i.e., several days) the overall reactivity of the remaining TOC from petrochemical sources (and likely many anthropogenic sources) is expected to be higher than that from biogenic precursors. The longer time scale associated with the evolution of carbon here indicates that petrochemical sources are likely to be processed in the atmosphere over a greater spatial scale compared to biogenic emissions, with effects on air quality and ecosystems which are yet unclear. While the TOC from biogenic precursors are mainly dominated by aerosols and long-lived small oxygenated VOCs after $\sim 1$ day oxidation, ${ }^{10}$ petrochemical emissions will retain much of their complex composition and relatively high reactivity for many days. This suggests that OS and/or other anthropogenic emissions and their oxidation products can easily be subject to long-range transport to remote areas.

The chemical properties of TOOC characterized in this study can also improve our understanding of the evolution, fate, and environmental impacts of OS emissions. First, the detailed chemical properties of TOOC derived in this work provide a potential means of predicting the deposition rates of the multitude of chemical species formed from OS emissions. ${ }^{11}$ The higher $\mathrm{OS}_{\mathrm{C}}$, lower volatility, and slower oxidation of TOOC from OS ore (or other heavier precursors) further suggests that dry deposition may be a more important fate compared to the TOOC from naphtha (or other lighter precursors), ${ }^{11}$ and it may be competitive with $\mathrm{OH}$ oxidative loss and/or SOA formation. Hence, it is expected that the results of this work can be used to better quantify the relative importance of these processes, ${ }^{12}$ improving our understanding of their subsequent impacts on downwind ecosystems. Second, the data in the current work can be used to better constrain the ozone production potential of OS emissions. Previous studies $^{64,65}$ have shown that alkanes can produce ozone after multiday oxidation (much longer than the time scale of unsaturated compounds such as alkenes and aromatics), which is similar to the photochemical ages studied here. As the ozone production rate is positively correlated with the $\mathrm{OH}$ reactivity of the products and dependent on $\mathrm{NO}_{x}$ levels, ${ }^{64}$ the $\mathrm{OH}$ reactivity of $\mathrm{OC}$ under different $\mathrm{NO}_{x}$ conditions in this study will improve the quantification of ozone production from OS emissions.

\section{ASSOCIATED CONTENT}

\section{Supporting Information}

The Supporting Information is available free of charge at https://pubs.acs.org/doi/10.1021/acs.est.1c02620.

Additional experimental details; calibrations and uncertainties of PTR-MS and CIMS; supplementary discussion of OFR and OC chemical properties; additional tables and figures of carbon closure and chemical parameters (PDF)

\section{AUTHOR INFORMATION}

\section{Corresponding Authors}

Kun Li - Air Quality Research Division, Environment and Climate Change Canada, Toronto, Ontario M3H 5T4, Canada; Laboratory of Atmospheric Chemistry, Paul Scherrer Institute, Villigen 5232, Switzerland; - orcid.org/ 0000-0003-2970-037X; Email: kun.li@psi.ch

John Liggio - Air Quality Research Division, Environment and Climate Change Canada, Toronto, Ontario M3H 5T4, Canada; (ㄷ) orcid.org/0000-0003-3683-4595; Email: john.liggio@canada.ca

\section{Authors}

Jeremy J. B. Wentzell - Air Quality Research Division, Environment and Climate Change Canada, Toronto, Ontario M3H 5T4, Canada

Qifan Liu - Air Quality Research Division, Environment and Climate Change Canada, Toronto, Ontario M3H 5T4, Canada; Present Address: Department of Chemistry, University of Toronto, Toronto, ON M3S 3H6, Canada; (1) orcid.org/0000-0003-0033-5313 
Amy Leithead - Air Quality Research Division, Environment and Climate Change Canada, Toronto, Ontario M3H 5T4, Canada

Samar G. Moussa - Air Quality Research Division, Environment and Climate Change Canada, Toronto, Ontario M3H 5T4, Canada

Michael J. Wheeler - Air Quality Research Division, Environment and Climate Change Canada, Toronto, Ontario M3H 5T4, Canada

Chong Han - Air Quality Research Division, Environment and Climate Change Canada, Toronto, Ontario M3H 5T4, Canada; Present Address: School of Metallurgy, Northeastern University, Shenyang 110819, China; () orcid.org/0000-0003-4828-0884

Patrick Lee - Air Quality Research Division, Environment and Climate Change Canada, Toronto, Ontario M3H 5T4, Canada

Shao-Meng Li - College of Environmental Sciences and Engineering, Peking University, Beijing 100871, China

Complete contact information is available at: https://pubs.acs.org/10.1021/acs.est.1c02620

\section{Notes}

The authors declare no competing financial interest.

\section{ACKNOWLEDGMENTS}

We thank Harald Stark and Jordan Krechmer for the helpful discussion in the CIMS calibration method and Zhe Peng for the helpful discussion in the OFR modeling. The authors acknowledge funding support from the Air Pollution program of Environment and Climate Change Canada (ECCC). This work was partially funded under the Oil Sands Monitoring (OSM) program. It is independent of any position of the OSM program. We thank the Canada's Oil Sands Innovation Alliance (COSIA) for the organization and provision of samples used in this paper. S.-M.L. was supported by the State Key Joint Laboratory of Environment Simulation and Pollution Control, College of Environmental Sciences and Engineering, Peking University.

\section{REFERENCES}

(1) Heald, C. L.; Kroll, J. H. The fuel of atmospheric chemistry: Toward a complete description of reactive organic carbon. Science Advances 2020, 6 (6), No. eaay8967.

(2) Safieddine, S. A.; Heald, C. L.; Henderson, B. H. The global nonmethane reactive organic carbon budget: A modeling perspective. Geophys. Res. Lett. 2017, 44 (8), 3897-3906.

(3) Hallquist, M.; Wenger, J. C.; Baltensperger, U.; Rudich, Y.; Simpson, D.; Claeys, M.; Dommen, J.; Donahue, N. M.; George, C.; Goldstein, A. H.; Hamilton, J. F.; Herrmann, H.; Hoffmann, T.; Iinuma, Y.; Jang, M.; Jenkin, M. E.; Jimenez, J. L.; Kiendler-Scharr, A.; Maenhaut, W.; McFiggans, G.; Mentel, T. F.; Monod, A.; Prevot, A. S. H.; Seinfeld, J. H.; Surratt, J. D.; Szmigielski, R.; Wildt, J. The formation, properties and impact of secondary organic aerosol: current and emerging issues. Atmos. Chem. Phys. 2009, 9 (14), 51555236.

(4) Goldstein, A. H.; Galbally, I. E. Known and Unexplored Organic Constituents in the Earth's Atmosphere. Environ. Sci. Technol. 2007, 41 (5), 1514-1521.

(5) Calvert, J. G.; Derwent, R. G.; Orlando, J. J.; Tyndall, G. S.; Wallington, T. J. Mechanisms of Atmospheric Oxidation of the Alkanes; Oxford University Press: 2008.
(6) Ziemann, P. J.; Atkinson, R. Kinetics, products, and mechanisms of secondary organic aerosol formation. Chem. Soc. Rev. 2012, 41 (19), 6582-605.

(7) Wennberg, P. O.; Bates, K. H.; Crounse, J. D.; Dodson, L. G.; McVay, R. C.; Mertens, L. A.; Nguyen, T. B.; Praske, E.; Schwantes, R. H.; Smarte, M. D.; St Clair, J. M.; Teng, A. P.; Zhang, X.; Seinfeld, J. H. Gas-Phase Reactions of Isoprene and Its Major Oxidation Products. Chem. Rev. 2018, 118 (7), 3337-3390.

(8) Lee, A.; Goldstein, A. H.; Keywood, M. D.; Gao, S.; Varutbangkul, V.; Bahreini, R.; Ng, N. L.; Flagan, R. C.; Seinfeld, J. H. Gas-phase products and secondary aerosol yields from the ozonolysis of ten different terpenes. J. Geophys. Res. 2006, 111 (D7), D07302.

(9) Lee, A.; Goldstein, A. H.; Kroll, J. H.; Ng, N. L.; Varutbangkul, V.; Flagan, R. C.; Seinfeld, J. H. Gas-phase products and secondary aerosol yields from the photooxidation of 16 different terpenes. $J$. Geophys. Res. 2006, 111 (D17), D17305.

(10) Isaacman-VanWertz, G.; Massoli, P.; O’Brien, R.; Lim, C.; Franklin, J. P.; Moss, J. A.; Hunter, J. F.; Nowak, J. B.; Canagaratna, M. R.; Misztal, P. K.; Arata, C.; Roscioli, J. R.; Herndon, S. T.; Onasch, T. B.; Lambe, A. T.; Jayne, J. T.; Su, L.; Knopf, D. A.; Goldstein, A. H.; Worsnop, D. R.; Kroll, J. H. Chemical evolution of atmospheric organic carbon over multiple generations of oxidation. Nat. Chem. 2018, 10, 462-468.

(11) Hodzic, A.; Aumont, B.; Knote, C.; Lee-Taylor, J.; Madronich, S.; Tyndall, G. Volatility dependence of Henry's law constants of condensable organics: Application to estimate depositional loss of secondary organic aerosols. Geophys. Res. Lett. 2014, 41 (13), 47954804.

(12) Knote, C.; Hodzic, A.; Jimenez, J. L. The effect of dry and wet deposition of condensable vapors on secondary organic aerosols concentrations over the continental US. Atmos. Chem. Phys. 2015, 15 (1), $1-18$.

(13) de Gouw, J. A.; Welsh-Bon, D.; Warneke, C.; Kuster, W. C.; Alexander, L.; Baker, A. K.; Beyersdorf, A. J.; Blake, D. R.; Canagaratna, M.; Celada, A. T.; Huey, L. G.; Junkermann, W.; Onasch, T. B.; Salcido, A.; Sjostedt, S. J.; Sullivan, A. P.; Tanner, D. J.; Vargas, O.; Weber, R. J.; Worsnop, D. R.; Yu, X. Y.; Zaveri, R. Emission and chemistry of organic carbon in the gas and aerosol phase at a sub-urban site near Mexico City in March 2006 during the MILAGRO study. Atmos. Chem. Phys. 2009, 9 (10), 3425-3442.

(14) Heald, C. L.; Goldstein, A. H.; Allan, J. D.; Aiken, A. C.; Apel, E.; Atlas, E. L.; Baker, A. K.; Bates, T. S.; Beyersdorf, A. J.; Blake, D. R.; Campos, T.; Coe, H.; Crounse, J. D.; DeCarlo, P. F.; de Gouw, J. A.; Dunlea, E. J.; Flocke, F. M.; Fried, A.; Goldan, P.; Griffin, R. J.; Herndon, S. C.; Holloway, J. S.; Holzinger, R.; Jimenez, J. L.; Junkermann, W.; Kuster, W. C.; Lewis, A. C.; Meinardi, S.; Millet, D. B.; Onasch, T.; Polidori, A.; Quinn, P. K.; Riemer, D. D.; Roberts, J. M.; Salcedo, D.; Sive, B.; Swanson, A. L.; Talbot, R.; Warneke, C.; Weber, R. J.; Weibring, P.; Wennberg, P. O.; Worsnop, D. R.; Wittig, A. E.; Zhang, R.; Zheng, J.; Zheng, W. Total observed organic carbon (TOOC) in the atmosphere: a synthesis of North American observations. Atmos. Chem. Phys. 2008, 8 (7), 2007-2025.

(15) Hunter, J. F.; Day, D. A.; Palm, B. B.; Yatavelli, R. L. N.; Chan, A. W. H.; Kaser, L.; Cappellin, L.; Hayes, P. L.; Cross, E. S.; Carrasquillo, A. J.; Campuzano-Jost, P.; Stark, H.; Zhao, Y.; Hohaus, T.; Smith, J. N.; Hansel, A.; Karl, T.; Goldstein, A. H.; Guenther, A.; Worsnop, Douglas R.; Thornton, J. A.; Heald, C. L.; Jimenez, J. L.; Kroll, J. H. Comprehensive characterization of atmospheric organic carbon at a forested site. Nat. Geosci. 2017, 10, 748-753.

(16) Isaacman-VanWertz, G.; Massoli, P.; O’Brien, R. E.; Nowak, J. B.; Canagaratna, M. R.; Jayne, J. T.; Worsnop, D. R.; Su, L.; Knopf, D. A.; Misztal, P. K.; Arata, C.; Goldstein, A. H.; Kroll, J. H. Using advanced mass spectrometry techniques to fully characterize atmospheric organic carbon: current capabilities and remaining gaps. Faraday Discuss. 2017, 200, 579-598.

(17) Price, D. J.; Day, D. A.; Pagonis, D.; Stark, H.; Algrim, L. B.; Handschy, A. V.; Liu, S.; Krechmer, J. E.; Miller, S. L.; Hunter, J. F.; de Gouw, J. A.; Ziemann, P. J.; Jimenez, J. L. Budgets of Organic 
Carbon Composition and Oxidation in Indoor Air. Environ. Sci. Technol. 2019, 53 (22), 13053-13063.

(18) Lackner, K. S. Can Fossil Carbon Fuel the 21st Century? Int. Geol. Rev. 2002, 44 (12), 1122-1133.

(19) Daily demand for crude oil worldwide from 2006 to 2020, with a forecast until 2026. Statista. https://www.statista.com/statistics/ 271823/daily-global-crude-oil-demand-since-2006/ (accessed 202006-13).

(20) Wang, H.; Ma, F.; Tong, X.; Liu, Z.; Zhang, X.; Wu, Z.; Li, D.; Wang, B.; Xie, Y.; Yang, L. Assessment of global unconventional oil and gas resources. Petroleum Exploration and Development 2016, 43 (6), 925-940.

(21) ST98: Alberta Energy Outlook. Alberta Energy Regulator, June 2021. https://www.aer.ca/providing-information/data-and-reports/ statistical-reports/st98.

(22) Li, S.-M.; Leithead, A.; Moussa, S. G.; Liggio, J.; Moran, M. D.; Wang, D.; Hayden, K.; Darlington, A.; Gordon, M.; Staebler, R.; Makar, P. A.; Stroud, C. A.; McLaren, R.; Liu, P. S. K.; O’Brien, J.; Mittermeier, R. L.; Zhang, J.; Marson, G.; Cober, S. G.; Wolde, M.; Wentzell, J. J. B. Differences between measured and reported volatile organic compound emissions from oil sands facilities in Alberta, Canada. Proc. Natl. Acad. Sci. U. S. A. 2017, 114 (19), E3756-E3765. (23) Tokarek, T. W.; Odame-Ankrah, C. A.; Huo, J. A.; McLaren, R.; Lee, A. K. Y.; Adam, M. G.; Willis, M. D.; Abbatt, J. P. D.; Mihele, C.; Darlington, A.; Mittermeier, R. L.; Strawbridge, K.; Hayden, K. L.; Olfert, J. S.; Schnitzler, E. G.; Brownsey, D. K.; Assad, F. V.; Wentworth, G. R.; Tevlin, A. G.; Worthy, D. E. J.; Li, S.-M.; Liggio, J.; Brook, J. R.; Osthoff, H. D. Principal component analysis of summertime ground site measurements in the Athabasca oil sands with a focus on analytically unresolved intermediate-volatility organic compounds. Atmos. Chem. Phys. 2018, 18 (24), 17819-17841.

(24) Liggio, J.; Li, S. M.; Hayden, K.; Taha, Y. M.; Stroud, C.; Darlington, A.; Drollette, B. D.; Gordon, M.; Lee, P.; Liu, P.; Leithead, A.; Moussa, S. G.; Wang, D.; O’Brien, J.; Mittermeier, R. L.; Brook, J. R.; Lu, G.; Staebler, R. M.; Han, Y.; Tokarek, T. W.; Osthoff, H. D.; Makar, P. A.; Zhang, J.; Plata, D. L.; Gentner, D. R. Oil sands operations as a large source of secondary organic aerosols. Nature 2016, 534 (7605), 91-94.

(25) Li, K.; Liggio, J.; Lee, P.; Han, C.; Liu, Q.; Li, S. M. Secondary organic aerosol formation from $\alpha$-pinene, alkanes and oil-sandsrelated precursors in a new oxidation flow reactor. Atmos. Chem. Phys. 2019, 19 (15), 9715-9731.

(26) Li, K.; Liggio, J.; Han, C.; Liu, Q.; Moussa, S. G.; Lee, P.; Li, S. M. Understanding the Impact of High-NOx Conditions on the Formation of Secondary Organic Aerosol in the Photooxidation of Oil Sand-Related Precursors. Environ. Sci. Technol. 2019, 53 (24), 1442014429.

(27) Hansel, A.; Scholz, W.; Mentler, B.; Fischer, L.; Berndt, T. Detection of $\mathrm{RO} 2$ radicals and other products from cyclohexene ozonolysis with $\mathrm{NH} 4+$ and acetate chemical ionization mass spectrometry. Atmos. Environ. 2018, 186, 248-255.

(28) Eddingsaas, N. C.; Loza, C. L.; Yee, L. D.; Seinfeld, J. H.; Wennberg, P. O. $\alpha$-pinene photooxidation under controlled chemical conditions - Part 1: Gas-phase composition in low- and high- $\mathrm{NO}_{\mathrm{x}}$ environments. Atmos. Chem. Phys. 2012, 12 (14), 6489-6504.

(29) Praske, E.; Otkjær, R. V.; Crounse, J. D.; Hethcox, J. C.; Stoltz, B. M.; Kjaergaard, H. G.; Wennberg, P. O. Atmospheric autoxidation is increasingly important in urban and suburban North America. Proc. Natl. Acad. Sci. U. S. A. 2018, 115 (1), 64-69.

(30) Zhao, D.; Schmitt, S. H.; Wang, M.; Acir, I.-H.; Tillmann, R.; Tan, Z.; Novelli, A.; Fuchs, H.; Pullinen, I.; Wegener, R.; Rohrer, F.; Wildt, J.; Kiendler-Scharr, A.; Wahner, A.; Mentel, T. F. Effects of $\mathrm{NOx}$ and $\mathrm{SO} 2$ on the secondary organic aerosol formation from photooxidation of $\alpha$-pinene and limonene. Atmos. Chem. Phys. 2018, 18 (3), 1611-1628.

(31) Xu, L.; Kollman, M. S.; Song, C.; Shilling, J. E.; Ng, N. L. Effects of NOx on the volatility of secondary organic aerosol from isoprene photooxidation. Environ. Sci. Technol. 2014, 48 (4), 225362.
(32) Khare, P.; Machesky, J.; Soto, R.; He, M.; Presto, A. A.; Gentner, D. R. Asphalt-related emissions are a major missing nontraditional source of secondary organic aerosol precursors. Science Advances 2020, 6 (36), No. eabb9785.

(33) Strausz, O. P.; Mojelsky, T. W.; Faraji, F.; Lown, E. M.; Peng, P. a. Additional Structural Details on Athabasca Asphaltene and Their Ramifications. Energy Fuels 1999, 13 (2), 207-227.

(34) Mohamad Shahimin, M. F.; Siddique, T. Sequential biodegradation of complex naphtha hydrocarbons under methanogenic conditions in two different oil sands tailings. Environ. Pollut. 2017, 221, 398-406.

(35) Lambe, A. T.; Onasch, T. B.; Croasdale, D. R.; Wright, J. P.; Martin, A. T.; Franklin, J. P.; Massoli, P.; Kroll, J. H.; Canagaratna, M. R.; Brune, W. H.; Worsnop, D. R.; Davidovits, P. Transitions from functionalization to fragmentation reactions of laboratory secondary organic aerosol (SOA) generated from the $\mathrm{OH}$ oxidation of alkane precursors. Environ. Sci. Technol. 2012, 46 (10), 5430-7.

(36) Lambe, A.; Massoli, P.; Zhang, X.; Canagaratna, M.; Nowak, J.; Daube, C.; Yan, C.; Nie, W.; Onasch, T.; Jayne, J.; Kolb, C.; Davidovits, P.; Worsnop, D.; Brune, W. Controlled nitric oxide production via $\mathrm{O}(\mathrm{ID})+\mathrm{N} 2 \mathrm{O}$ reactions for use in oxidation flow reactor studies. Atmos. Meas. Tech. 2017, 10 (6), 2283-2298.

(37) Peng, Z.; Palm, B. B.; Day, D. A.; Talukdar, R. K.; Hu, W.; Lambe, A. T.; Brune, W. H.; Jimenez, J. L. Model Evaluation of New Techniques for Maintaining High-NO Conditions in Oxidation Flow Reactors for the Study of OH-Initiated Atmospheric Chemistry. ACS Earth and Space Chemistry 2018, 2 (2), 72-86.

(38) Veres, P.; Gilman, J. B.; Roberts, J. M.; Kuster, W. C.; Warneke, C.; Burling, I. R.; de Gouw, J. Development and validation of a portable gas phase standard generation and calibration system for volatile organic compounds. Atmos. Meas. Tech. 2010, 3 (3), 683691.

(39) DeCarlo, P. F.; Kimmel, J. R.; Trimborn, A.; Northway, M. J.; Jayne, J. T.; Aiken, A. C.; Gonin, M.; Fuhrer, K.; Horvath, T.; Docherty, K. S.; Worsnop, D. R.; Jimenez, J. L. Field-Deployable, High-Resolution, Time-of-Flight Aerosol Mass Spectrometer. Anal. Chem. 2006, 78 (24), 8281-8289.

(40) Jordan, A.; Haidacher, S.; Hanel, G.; Hartungen, E.; Märk, L.; Seehauser, H.; Schottkowsky, R.; Sulzer, P.; Märk, T. D. A high resolution and high sensitivity proton-transfer-reaction time-of-flight mass spectrometer (PTR-TOF-MS). Int. J. Mass Spectrom. 2009, 286 $(2-3), 122-128$.

(41) Lee, B. H.; Lopez-Hilfiker, F. D.; Mohr, C.; Kurten, T.; Worsnop, D. R.; Thornton, J. A. An iodide-adduct high-resolution time-of-flight chemical-ionization mass spectrometer: application to atmospheric inorganic and organic compounds. Environ. Sci. Technol. 2014, 48 (11), 6309-17.

(42) Cappellin, L.; Karl, T.; Probst, M.; Ismailova, O.; Winkler, P. M.; Soukoulis, C.; Aprea, E.; Mark, T. D.; Gasperi, F.; Biasioli, F. On quantitative determination of volatile organic compound concentrations using proton transfer reaction time-of-flight mass spectrometry. Environ. Sci. Technol. 2012, 46 (4), 2283-90.

(43) Lopez-Hilfiker, F. D.; Iyer, S.; Mohr, C.; Lee, B. H.; D’Ambro, E. L.; Kurten, T.; Thornton, J. A. Constraining the sensitivity of iodide adduct chemical ionization mass spectrometry to multifunctional organic molecules using the collision limit and thermodynamic stability of iodide ion adducts. Atmos. Meas. Tech. 2016, 9 (4), 15051512.

(44) Iyer, S.; Lopez-Hilfiker, F.; Lee, B. H.; Thornton, J. A.; Kurten, T. Modeling the Detection of Organic and Inorganic Compounds Using Iodide-Based Chemical Ionization. J. Phys. Chem. A 2016, 120 (4), 576-87.

(45) Kroll, J. H.; Donahue, N. M.; Jimenez, J. L.; Kessler, S. H.; Canagaratna, M. R.; Wilson, K. R.; Altieri, K. E.; Mazzoleni, L. R.; Wozniak, A. S.; Bluhm, H.; Mysak, E. R.; Smith, J. D.; Kolb, C. E.; Worsnop, D. R. Carbon oxidation state as a metric for describing the chemistry of atmospheric organic aerosol. Nat. Chem. 2011, 3 (2), 133-9. 
(46) PubChem. National Institutes of Health. https://pubchem.ncbi. nlm.nih.gov/ (accessed 2020-05-20).

(47) Li, Y.; Pöschl, U.; Shiraiwa, M. Molecular corridors and parameterizations of volatility in the chemical evolution of organic aerosols. Atmos. Chem. Phys. 2016, 16 (5), 3327-3344.

(48) Manion, J. A.; Huie, R. E.; Levin, R. D.; Burgess, D. R., Jr.; Orkin, V. L.; Tsang, W.; McGivern, W. S.; Hudgens, J. W.; Knyazev, V. D.; Atkinson, D. B.; Chai, E.; Tereza, A. M.; Lin, C.-Y.; Allison, T. C.; Mallard, W. G.; Westley, F.; Herron, J. T.; Hampson, R. F.; Frizzell, D. H. NIST Chemical Kinetics Database, NIST Standard Reference Database 17, Ver. 7.0 (Web Version). National Institute of Standards and Technology. 2015. http://kinetics.nist.gov/.

(49) Atkinson, R.; Arey, J. Atmospheric Degradation of Volatile Organic Compounds. Chem. Rev. 2003, 103 (12), 4605-4638.

(50) Donahue, N. M.; Chuang, W.; Epstein, S. A.; Kroll, J. H.; Worsnop, D. R.; Robinson, A. L.; Adams, P. J.; Pandis, S. N. Why do organic aerosols exist? Understanding aerosol lifetimes using the twodimensional volatility basis set. Environmental Chemistry 2013, 10 (3), 151.

(51) Mao, J.; Ren, X.; Brune, W. H.; Olson, J. R.; Crawford, J. H.; Fried, A.; Huey, L. G.; Cohen, R. C.; Heikes, B.; Singh, H. B.; Blake, D. R.; Sachse, G. W.; Diskin, G. S.; Hall, S. R.; Shetter, R. E. Airborne measurement of $\mathrm{OH}$ reactivity during INTEX-B. Atmos. Chem. Phys. 2009, 9 (1), 163-173.

(52) Gueneron, M.; Erickson, M. H.; VanderSchelden, G. S.; Jobson, B. T. PTR-MS fragmentation patterns of gasoline hydrocarbons. Int. J. Mass Spectrom. 2015, 379, 97-109.

(53) Peng, Z.; Jimenez, J. L. Radical chemistry in oxidation flow reactors for atmospheric chemistry research. Chem. Soc. Rev. 2020, 49 (9), 2570-2616.

(54) Peeters, J.; Vereecken, L.; Fantechi, G. The detailed mechanism of the $\mathrm{OH}$-initiated atmospheric oxidation of $\alpha$-pinene: a theoretical study. Phys. Chem. Chem. Phys. 2001, 3 (24), 5489-5504.

(55) Capouet, M.; Peeters, J.; Noziere, B.; Müller, J. F. Alpha-pinene oxidation by $\mathrm{OH}$ : simulations of laboratory experiments. Atmos. Chem. Phys. 2004, 4 (9/10), 2285-2311.

(56) Calvert, J. G.; Mellouki, A.; Orlando, J. J.; Pilling, M. J.; Wallington, T. J. Mechanisms of Atmospheric Oxidation of the Oxygenates; Oxford University Press: 2011.

(57) Jenkin, M. E.; Valorso, R.; Aumont, B.; Rickard, A. R.; Wallington, T. J. Estimation of rate coefficients and branching ratios for gas-phase reactions of $\mathrm{OH}$ with aliphatic organic compounds for use in automated mechanism construction. Atmos. Chem. Phys. 2018, 18 (13), 9297-9328.

(58) Peng, Z.; Lee-Taylor, J.; Stark, H.; Orlando, J. J.; Aumont, B.; Jimenez, J. L. Evolution of $\mathrm{OH}$ reactivity in low-NO volatile organic compound photooxidation investigated by the fully explicit GECKOA model. Atmos. Chem. Phys. Discuss. [preprint] 2021, DOI: 10.5194/ acp-2021-118.

(59) Hanst, P. L.; Gay, B. W. Atmospheric oxidation of hydrocarbons: Formation of hydroperoxides and peroxyacids. Atmos. Environ. (1967-1989) 1983, 17 (11), 2259-2265.

(60) Hatakeyama, S.; Ohno, M.; Weng, J.; Takagi, H.; Akimoto, H. Mechanism for the formation of gaseous and particulate products from ozone-cycloalkene reactions in air. Environ. Sci. Technol. 1987, $21(1), 52-57$.

(61) Donahue, N. M.; Kroll, J. H.; Pandis, S. N.; Robinson, A. L. A two-dimensional volatility basis set - Part 2: Diagnostics of organicaerosol evolution. Atmos. Chem. Phys. 2012, 12 (2), 615-634.

(62) Kroll, J. H.; Lim, C. Y.; Kessler, S. H.; Wilson, K. R. Heterogeneous Oxidation of Atmospheric Organic Aerosol: Kinetics of Changes to the Amount and Oxidation State of Particle-Phase Organic Carbon. J. Phys. Chem. A 2015, 119 (44), 10767-83.

(63) Sarrafzadeh, M.; Wildt, J.; Pullinen, I.; Springer, M.; Kleist, E.; Tillmann, R.; Schmitt, S. H.; Wu, C.; Mentel, T. F.; Zhao, D.; Hastie, D. R.; Kiendler-Scharr, A. Impact of $\mathrm{NOx}$ and $\mathrm{OH}$ on secondary organic aerosol formation from $\beta$-pinene photooxidation. Atmos. Chem. Phys. 2016, 16 (17), 11237-11248.
(64) Butler, T. M.; Lawrence, M. G.; Taraborrelli, D.; Lelieveld, J. Multi-day ozone production potential of volatile organic compounds calculated with a tagging approach. Atmos. Environ. 2011, 45 (24), 4082-4090.

(65) Pusede, S. E.; Steiner, A. L.; Cohen, R. C. Temperature and Recent Trends in the Chemistry of Continental Surface Ozone. Chem. Rev. 2015, 115 (10), 3898-3918. 